\title{
Enhanced Recovery After Cardiac Surgery: Where Do We Stand?
}

\author{
Alexander Gebauer ${ }^{1}$ (i) - Johannes Petersen ${ }^{1}$ - Johanna Konertz ${ }^{1}$ - Jens Brickwedel ${ }^{1}$ - Leonie Schulte-Uentrop ${ }^{2}$. \\ Hermann Reichenspurner ${ }^{1}$ • Evaldas Girdauskas ${ }^{1,3}$
}

Accepted: 31 May 2021 / Published online: 29 June 2021

(C) The Author(s) 2021

\begin{abstract}
Purpose of Review Enhanced recovery after surgery (ERAS) protocols are multimodal and multi-professional strategies to enhance postoperative convalescence and thereby reduce the length of hospital stay and hospital-associated complications. This review provides an up-to-date overview about basic principles of enhanced recovery after surgery protocols, their transfer into cardiac surgery, and their current state of evidence. It is supposed to offer clinical implications for further adaptations and implementations of such protocols in cardiac surgery.

Recent Findings ERAS protocols are a story of success in numerous surgical disciplines and led to a paradigm shift in perioperative care and the establishment of ERAS Cardiac Society, a non-profit organization that provides evidence-based guidelines and recommendations for further development of enhanced recovery protocols, trying to harmonize the many existing efforts of individual approaches for cardiac surgery.

Summary Promising results from comprehensive ERAS protocols in cardiac surgery emerged. Nevertheless, there is a paucity of high-quality data about holistic approaches in cardiac surgery and further efforts need to be promoted.
\end{abstract}

Keywords ERAS $\cdot$ Enhanced recovery $\cdot$ Fast Track $\cdot$ Cardiac surgery $\cdot$ Minimally invasive surgery

\section{Introduction}

Enhanced recovery after surgery (ERAS) protocols are multimodal and multi-professional strategies to reduce physiological and psychological stress and thus decrease the appearance of postoperative complications and the length of hospital stay [1-3].

Initially established by Danish surgeon Dr. Kehlet in 1997, ERAS protocols proved to be efficient in colorectal surgery, demonstrating a reduction of healthcare-associated infections

This article is part of the Topical Collection on Cardiovascular Anesthesia

Alexander Gebauer

alexander.gebauer@uke.de

1 Department of Cardiovascular Surgery, University Heart \& Vascular Center Hamburg, Hamburg, Germany

2 Department of Anesthesiology, Center of Anesthesiology and Intensive Care Medicine, University Medical Center Hamburg-Eppendorf, Hamburg, Germany

3 Department of Cardiothoracic Surgery, University Medical Center Augsburg, Augsburg, Germany and major advantages in length of hospital stays and costeffectiveness $[4,5]$. Those findings resulted in a paradigm shift in perioperative care, leading to the adoption of such protocols in a variety of surgical disciplines [6]. Numerous protocols, often referred to as "Fast Track" surgery, tend to apply only certain elements of ERAS principles, promoting a well-sounding but unprotected concept, often useful to attract media and patient attention, but rarely appropriate to live up to the holistic approach of enhanced recovery protocols. ERAS protocols were designed to cover up the entire journey of the patient, starting with preoperative patient education up to the point of early ambulation and follow-up care [7••]. Ultimately, ERAS society was established to deliver certified and evidence-based recommendations for pancreatic surgery [8], bariatrics [9], urology [10], otolaryngeal head and neck surgery [11], gynecology [12], and many more in development.

Cardiac surgery (CS) in particular offers a wide variety of complex pathologies, leads to high healthcare expenditures, and has to care for increasingly old patients who typically present with multiple comorbidities. That adds to the challenge of designing protocols that provide good treatment outcomes while having costs in control. With ongoing progress in developing less invasive surgical approaches and decreasing 
lengths on cardiopulmonary bypass (CPB), the number of patients being eligible for ERAS protocols in CS is increasing. Nonetheless, there is an apparent paucity of high-quality data on ERAS protocols in CS. For this reason, adoption and further enhancement of ERAS programs should be encouraged.

\section{Basic Principles of ERAS}

As a non-profit organization founded in 2010, ERAS society has published a range of guidelines and consensus papers for numerous surgical disciplines since then [7••]. Main principles of all modern ERAS protocols that apply to every surgical discipline are (a) providing extended patient information, (b) the reduction and modification of posttraumatic stress, (c) efficient analgesia, and (d) maintaining or restoring patient autonomy [13•].

\section{(a) Extended patient information}

Patient information in enhanced surgery protocols exceeds the traditional form of information and consent, which is often focused on the forensic aspects of possible complications. It is rather seen as a psychologically educative measure to improve mental readiness for surgery. It includes detailed information about the expected process and the patient's active role in his or her recovery. This kind of information and education is deemed to reduce the imbalance of knowledge about what is going to happen to the patient in the course of the hospital stay and is supposed to allow for motivation through inclusion. It has shown to improve the transition from hospital to community [14] and can reduce fear and postoperative analgetic use $[15,16]$. Reduction of fear and analgetic use, on the other hand, might help improve postoperative convalescence [17, $18]$.

\section{(b) Reduction of posttraumatic stress}

Utilization of minimally invasive surgery goes hand in hand with ERAS methodology, as a reduction of trauma results in a reduction of inflammatory stress response, fewer postoperative complications, and shorter hospital length of stay (LOS) $[19,20]$. Creating smaller access trauma therefore might reduce pain and analgetic use.

A new nutritional intake regimen, disregarding the longexisting practice of preoperative fasting in favor of oral carbohydrate loading, could demonstrate a positive effect on postoperative insulin resistance [21]. A reduction in insulin resistance beneficially alters the catabolic response following surgical trauma and eases the metabolic changes of postoperative stress response [22]. A third component in the reduction of posttraumatic stress is early mobilization as it plays an important role in the prevention of muscular and cardiovascular deconditioning [23]. Recovery can be accelerated and appearance of respiratory infections and venous thrombembolisms can be reduced [7••].

\section{(c) Analgesia}

Inadequate perioperative analgesia results in sympathetic activation which can lead to the development of delayed gastrointestinal motility or other organ dysfunctions [5].

Pain-free patients, on the other hand, showed a reduction of postoperative complications and hospital LOS [24]. For enhanced recovery protocols, sufficient analgesia is a matter of utmost importance, as early mobilization and frequent physiotherapy units after surgery demand for active and collaborating patients.

\section{(d) Patient autonomy}

Even with possible restrictions in their everyday life caused by a disease, most patients lead a more or less independent and self-regulated life. A hospital stay marks a severe interference in a patient's autonomy. Tubes, catheters, and restrictions might limit the movement; there are regulations to follow and schedules to stick to. Hence, it is a central aspect of ERAS protocols to support patients in regaining their autonomy as soon as possible, utilizing all of the resources mentioned above.

\section{ERAS Cardiac and Certified Guidelines}

The successful implementation of abovementioned ERAS key elements in many non-cardiac surgery disciplines set the foundation for the establishment of ERAS Cardiac Society, a subgroup within ERAS Society. The multitude of complex pathologies, surgical approaches, and coexisting comorbidities in CS pose a great challenge to the development of comprehensive protocols. Additionally, the use of CPB triggers systemic inflammatory response syndrome, which complicates the postoperative recovery phase [25]. Preexisting protocols in CS suggested feasibility of applying certain elements of ERAS [26, 27], while numerous studies demonstrated that an early extubation is safe [28] and LOS on the intensive care unit (ICU) can be significantly shortened [29, 30]. Furthermore, the establishment of short-acting narcotics proved to be beneficial for early extubation and helped decrease ICU LOS in consequence of shorter ventilation times [31]. Nevertheless, reproducible guidelines that consider the complete perioperative process of ERAS in CS were not available. For this reason, newly founded ERAS Cardiac Society worked out evidence-based expert consensus recommendations on the basis of ERAS principles. A systematic literature review process to focus aspects of promising approaches and harmonize them into a scalable guideline led to the publication of the first ERACS guidelines manuscript [32••]. It provides a 
summarization of key elements for implementation, marked with class of evidence and level of recommendation. Graduation of evidence and recommendation was performed according to "The evolution and future of ACC/AHA clinical practice guidelines" from Jacobs et al. [33]. A selection of key recommendations from class I to class IIb are summarized in Table 1. While some recommended elements like goaldirected fluid therapy and early extubation might already be well established, some others might be more unfamiliar to some cardiac specialists. Some recommendations will need fundamental changes, which require a realignment of infrastructure and human resources. Offering a prehabilitation program, for example, requires an interdisciplinary collaboration, involving representatives from every involved profession (e.g., physiotherapy, cardiac surgeon, anesthesiologist), weeks prior to surgery. Feasible programs to assess a patient's eligibility and to evaluate the programs efficacy are necessary. An example that makes clear that implementation of ERAS in CS is not only a matter of applying a protocol, but that it requires a willingness to change and break with longestablished patterns. Salenger et al. recently published a guideline which emphasizes the complexity of successful implementation [34••]. Forming an ERAS program for CS is described as a multilayered process, starting with communicating the need for change. The following steps need to be a gap analysis in current organizational structures and a substantial team building. Once a feasible program is designed, monitoring compliance is challenging but essential. An implementation checklist is attached to the publication in order to encourage and facilitate a deployment in every setting.

Table 1 Summarization of recommendations adapted from "Guidelines for Perioperative Care in Cardiac Surgery Enhanced Recovery After Surgery Society Recommendation" Engelman et al. [32••]

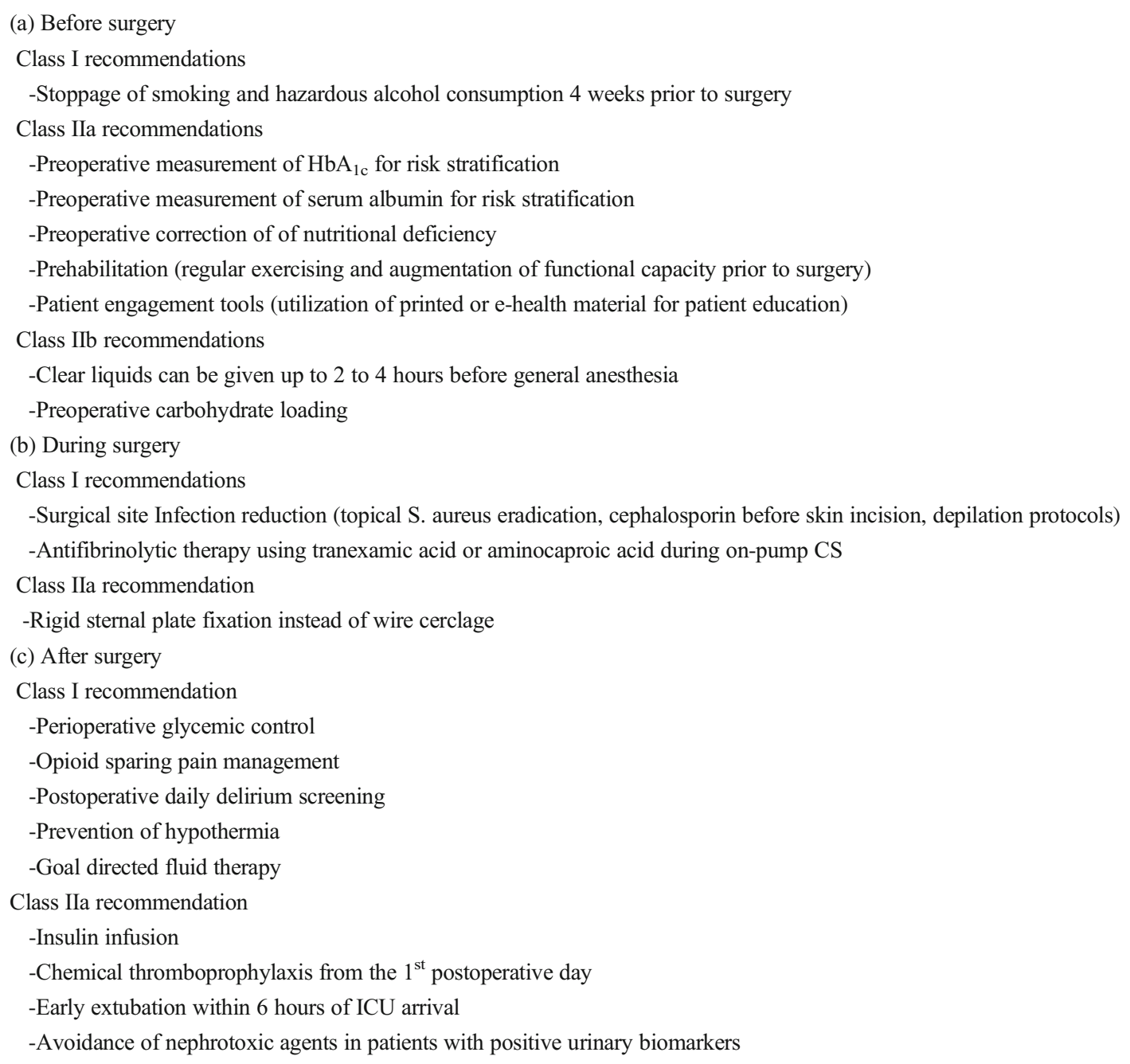




\section{Current Adaptations of ERAS in Cardiac Surgery}

In 2016, Wong et al. provided a third update to a systematic Cochrane database review, including 28 controlled trials that compared Fast Track care to routine care in adult cardiac surgery [30]. Fast Track protocols needed to contain a time-directed extubation protocol or usage of low-dose opioid-based general anesthesia to be considered. Fast Track protocols proved to be noninferior regarding postoperative complications and mortality in low- to moderate-risk patients. Although ICU LOS and time to extubation were significantly reduced in both Fast Track protocols, no differences in total hospital LOS were shown.

Fleming et al. contributed to ERAS by implementing an enhanced recovery protocol in a prospective observational study, comparing 52 patients undergoing CS after implementation of an ERAS protocol to 53 historic patients [26]. The protocol was based on recommendations from a consensus review in colorectal surgery, containing a more holistic perioperative approach. Detailed preoperative patient education, avoidance of prolonged fasting periods prior to surgery, preoperative carbohydrate beverages, optimization of analgesia with avoidance of long-acting opioids, prevention of postoperative nausea and vomiting, early enteral nutrition postoperatively, and early mobilization were applied. As a result, significantly fewer patients in the ERAS group presented with one or more postoperative complications. Additionally, reduced postoperative pain scores were documented. Hospital LOS remained unchanged in both groups.

The randomized clinical trial of $\mathrm{Li}$ et al. randomly assigned a total of 226 patients to a routine group or ERAS pathway [35]. Preoperative elements of the comprehensive protocol contained preoperative patient education and psychological counselling, as well as an erythropoietin injection and carbohydrate loading. Patients received a paravertebral nerve block for pain management. After surgery, catheters and tubes were removed on the first postoperative day and injection of erythropoietin was continued until the patient's hemoglobin level was above $10 \mathrm{~g} / \mathrm{dl}$. A significant reduction in major postoperative complications, such as acute renal failure, delirium, stroke, infarction, or heart block, was shown. Patients showed no differences in adverse events on 1, 3, and 6 months of follow-up after hospital discharge.

Di Eusanio et al. demonstrated safety and feasibility of minimally invasive aortic valve surgery, using rapid deployment valves in combination with a minimally invasive extracorporal circulation system [36]. Anesthetic management included low-dose opioid-based anesthesia, normothermic temperature management, a time-directed extubation protocol, and early onset of physiotherapy units and rehabilitation programs. Despite robust evidence missing, the overall reduction of surgical stress is expected to be associated with faster recovery and increased patient comfort.
The most extensive implementation of an enhanced recovery protocol in CS yet was described by Williams et al., who published the 1-year results of the first US-based ERAS cardiac program in 2019 [37॰]. The program included preoperative patient education, carbohydrate loading, opioid-sparing analgetic management, goal-directed insulin infusions, and rigorous bowel management. A total of 489 historic patients were compared to 443 patients undergoing ERAS protocol. A significant reduction in gastrointestinal complications, hospital, and ICU LOS was demonstrated and patient as well as staff satisfaction was increased.

At the University Heart and Vascular Center Hamburg, our group established an enhanced recovery protocol for minimally invasive heart valve pathologies [38]. Key elements of this protocol are a dedicated prehabilitation program, on-table extubation in the OR, and early postoperative mobilization. Establishment of the ERAS program resulted in safe and fast postoperative recovery of the patients and an economic benefit of up to $1900 €$ per patient [39]. The data collected in this retrospective cohort analysis made way for the INCREASE study (INterdisziplinäre und sektorenübergreifende Versorgung in der HerzChiRurgiE am Beispiel von minimal-invASiven Herzklappeneingriffen), a randomized clinical trial, which will start in June 2021 and is expected to provide high-quality data about the organization and execution of ERAS protocol in the minimally invasive treatment of heart valve pathologies and their potential transfer into standard-of-care treatment.

\section{Conclusion}

After the triumphal procession of ERAS in a variety of surgical specialties, promising results from comprehensive protocols in CS are gradually emerging. The many efforts being undertaken indicate an increasing willingness to shape inclusive future programs that cover up the entire journey of the patient, showing integration and improvement of pre-, intra-, and postoperative elements. After implementation of the ERAS protocols, it becomes clear that they could not only demonstrate a noninferiority but even contribute to the safety of specific patient collectives undergoing CS. Due to the safety and benefits of ERAS, it will play a key role in modern CS in the near future.

The relatively slow adoption of evidence-based elements, although some of the knowledge has been around for a long time, emphasizes the importance of communicating the need for change. In times when incremental professionalization in healthcare may have a tendency of driving different professions further apart, than to make them work together in a better way, ERAS can contribute to a manner of interdisciplinarity and cooperation. Although the convenience of sticking to reliable workflows and procedures is comprehensible, it has to 
be a matter of duty for a contemporary clinician to strive for a patient-centered and all-embracing healthcare system.

Funding Open Access funding enabled and organized by Projekt DEAL.

\section{Declarations}

Conflict of Interest Alexander Gebauer ${ }^{1}$, Dr. Johannes Petersen ${ }^{1}$, Johanna Konertz $^{1,}$ Dr. Jens Brickwedel ${ }^{1}$, Dr. Leonie Schulte-Uentrop ${ }^{1}$, Prof. Dr. Dr. Hermann Reichenspurner ${ }^{1}$, Prof. Dr. Evaldas Girdauskas ${ }^{1,2}$ declare they have no conflict of interest.

Human and Animal Rights and Informed Consent All reported studies/ experiments with human or animal subjects performed by the authors have been previously published and complied with all applicable ethical standards (including the Helsinki declaration and its amendments, institutional/national research committee standards, and international/national/institutional guidelines).

Open Access This article is licensed under a Creative Commons Attribution 4.0 International License, which permits use, sharing, adaptation, distribution and reproduction in any medium or format, as long as you give appropriate credit to the original author(s) and the source, provide a link to the Creative Commons licence, and indicate if changes were made. The images or other third party material in this article are included in the article's Creative Commons licence, unless indicated otherwise in a credit line to the material. If material is not included in the article's Creative Commons licence and your intended use is not permitted by statutory regulation or exceeds the permitted use, you will need to obtain permission directly from the copyright holder. To view a copy of this licence, visit http://creativecommons.org/licenses/by/4.0/.

\section{References}

Papers of particular interest, published recently, have been highlighted as:

- Of importance

•- Of major importance

1. Firoozfard B, Christensen T, Kristensen JK, Mogensen S, Kehlet H. Fast-track open transperitoneal nephrectomy. Scand J Urol Nephrol. 2003;37(4):305-8.

2. Kehlet H. Organizing postoperative accelerated recovery programs. Reg Anesth. 1996;21(6 Suppl):149-51.

3. Kehlet H. Multimodal approach to control postoperative pathophysiology and rehabilitation. Br J Anaesth. 1997;78(5):606-17.

4. Eskicioglu C, Forbes SS, Aarts MA, Okrainec A, McLeod RS. Enhanced recovery after surgery (ERAS) programs for patients having colorectal surgery: a meta-analysis of randomized trials. J Gastrointest Surg. 2009;13(12):2321-9.

5. Feldheiser A, Aziz O, Baldini G, Cox BP, Fearon KC, Feldman LS, et al. Enhanced Recovery After Surgery (ERAS) for gastrointestinal surgery, part 2: consensus statement for anaesthesia practice. Acta Anaesthesiol Scand. 2016;60(3):289-334.

6. Langelotz C, Spies C, Muller JM, Schwenk W. "Fast-track"-rehabilitation in surgery, a multimodal concept. Acta Chir Belg. 2005;105(6):555-9.
7.• Ljungqvist O, Francis KK, Urman R. Enhanced recovery after surgery a complete guide to optimizing outcomes. 1st ed: Springer International Publishing; 2020. XXIII, 654 p. This book provides a complete description of the history of ERAS, its essentials, the pathophysiology behind it and a detailed guidance through all the elements of the program in non-cardiac surgery fields. It is the standard work for enhanced recovery.

8. Melloul E, Lassen K, Roulin D, Grass F, Perinel J, Adham M, et al. Guidelines for perioperative care for pancreatoduodenectomy: Enhanced Recovery After Surgery (ERAS) Recommendations 2019. World J Surg. 2020;44(7):2056-84.

9. Thorell A, MacCormick AD, Awad S, Reynolds N, Roulin D, Demartines N, et al. Guidelines for perioperative care in bariatric surgery: Enhanced Recovery After Surgery (ERAS) Society Recommendations. World J Surg. 2016;40(9):2065-83.

10. Cerantola Y, Valerio M, Persson B, Jichlinski P, Ljungqvist O, Hubner $\mathrm{M}$, et al. Guidelines for perioperative care after radical cystectomy for bladder cancer: Enhanced Recovery After Surgery (ERAS(®)) society recommendations. Clin Nutr. 2013;32(6):879-87.

11. Dort JC, Farwell DG, Findlay M, Huber GF, Kerr P, Shea-Budgell MA, et al. Optimal perioperative care in major head and neck cancer surgery with free flap reconstruction: a consensus review and recommendations from the Enhanced Recovery After Surgery Society. JAMA Otolaryngology-Head \& Neck Surgery. 2017;143(3):292-303.

12. Nelson G, Altman AD, Nick A, Meyer LA, Ramirez PT, Achtari C, et al. Guidelines for pre- and intra-operative care in gynecologic/ oncology surgery: Enhanced Recovery After Surgery (ERAS®) Society recommendations-part I. Gynecol Oncol. 2016;140(2):313-22.

13. Schwenk W, Spies C, Müller J. Fast Track in der operativen Medizin. 1st ed. Berlin Heidelberg: Springer-Verlag; 2009. p. XIV, 786. This book provides a compact overview for ERAS in surgery, gynecology, urology, and nursing and serves as a reference book for the implementation of ERAS in these disciplines

14. Arthur HM, Daniels C, McKelvie R, Hirsh J, Rush B. Effect of a preoperative intervention on preoperative and postoperative outcomes in low-risk patients awaiting elective coronary artery bypass graft surgery. A randomized, controlled trial. Ann Intern Med. 2000;133(4):253-62.

15. Kehlet H, Wilmore DW. Fast-track surgery. Br J Surg. 2005;92(1): 3-4.

16. Egbert LD, Battit GE, Welch CE, Bartlett MK. Reduction of postoperative pain by encouragement and instruction of patients. A study of doctor-patient rapport. N Engl J Med. 1964;270:825-7.

17. Kehlet H, Holte K. Effect of postoperative analgesia on surgical outcome. Br J Anaesth. 2001;87(1):62-72.

18. Johnston M, Vögele C. Benefits of psychological preparation for surgery: a meta-analysis. Ann Behav Med. 1993:245-56.

19. Kim TK, Yoon JR. Comparison of the neuroendocrine and inflammatory responses after laparoscopic and abdominal hysterectomy. Korean J Anesthesiol. 2010;59(4):265-9.

20. Sood A, Meyer CP, Abdollah F, Sammon JD, Sun M, Lipsitz SR, et al. Minimally invasive surgery and its impact on 30-day postoperative complications, unplanned readmissions and mortality. Br J Surg. 2017;104(10):1372-81.

21. Smith MD, McCall J, Plank L, Herbison GP, Soop M, Nygren J. Preoperative carbohydrate treatment for enhancing recovery after elective surgery. Cochrane Database Syst Rev. 2014;8:Cd009161.

22. Ljungqvist $\mathrm{O}$. Modulating postoperative insulin resistance by preoperative carbohydrate loading. Best Pract Res Clin Anaesthesiol. 2009;23(4):401-9.

23. Epstein NE. A review article on the benefits of early mobilization following spinal surgery and other medical/surgical procedures. Surg Neurol Int. 2014;5(Suppl 3):S66-73.

24. Gustafsson UO, Scott MJ, Hubner M, Nygren J, Demartines N, Francis $\mathrm{N}$, et al. Guidelines for perioperative care in elective colorectal surgery: 
Enhanced Recovery After Surgery (ERAS(®)) Society Recommendations: 2018. World J Surg. 2019;43(3):659-95.

25. Hess PJ Jr. Systemic inflammatory response to coronary artery bypass graft surgery. Am J Health Syst Pharm. 2005;62(18 Suppl 4):S6-9.

26. Fleming IO, Garratt C, Guha R, Desai J, Chaubey S, Wang Y, et al. Aggregation of marginal gains in cardiac surgery: feasibility of a perioperative care bundle for enhanced recovery in cardiac surgical patients. J Cardiothorac Vasc Anesth. 2016;30(3):665-70.

27. Toraman F, Evrenkaya S, Yuce M, Goksel O, Karabulut H, Alhan C. Fast-track recovery in noncoronary cardiac surgery patients. Heart Surg Forum. 2005;8(1):E61-4.

28. Engelman RM. Mechanisms to reduce hospital stays. Ann Thorac Surg. 1996;61(2 Suppl):S26-9 discussion S33-4.

29. Ender J, Borger MA, Scholz M, Funkat AK, Anwar N, Sommer M, et al. Cardiac surgery fast-track treatment in a postanesthetic care unit: six-month results of the Leipzig fast-track concept. Anesthesiology. 2008;109(1):61-6.

30. Wong WT, Lai VK, Chee YE, Lee A. Fast-track cardiac care for adult cardiac surgical patients. Cochrane Database Syst Rev. 2016;9:CD003587.

31. Cheng DC. Pro: early extubation after cardiac surgery decreases intensive care unit stay and cost. J Cardiothorac Vasc Anesth. 1995;9(4):460-4.

32.• Engelman DT, Ben Ali W, Williams JB, Perrault LP, Reddy VS, Arora RC, et al. Guidelines for perioperative care in cardiac surgery: Enhanced Recovery After Surgery Society Recommendations. JAMA Surg. 2019;154(8):755-66 A very important paper for further adaption of ERAS in cardiac surgery. After performing an extensive literature review, the authors provide a list of elements that should or should not be included in a comprehensive ERAS protocol in cardiac surgery. The class of evidence and level of recommendation are given for each element.

33. Jacobs AK, Anderson JL, Halperin JL. The evolution and future of ACC/AHA clinical practice guidelines: a 30-year journey: a report of the American College of Cardiology/American Heart
Association Task Force on Practice Guidelines. J Am Coll Cardiol. 2014;64(13):1373-84.

34.• Salenger R, Morton-Bailey V, Grant M, Gregory A, Williams JB, Engelman DT. Cardiac enhanced recovery after surgery: a guide to team building and successful implementation. Semin Thorac Cardiovasc Surg. 2020;32(2):187-96 Despite the growing number of articles issuing ERAS in cardiac surgery, the actual implementation of an ERAS program is a much underrepresented topic. This article provides a step by step implementation guideline and facilitates the execution by attaching an implementation-checklist.

35. Li M, Zhang J, Gan TJ, Qin G, Wang L, Zhu M, et al. Enhanced recovery after surgery pathway for patients undergoing cardiac surgery: a randomized clinical trial. Eur J Cardiothorac Surg. 2018;54(3):491-7.

36. Di Eusanio M, Vessella W, Carozza R, Capestro F, D'Alfonso A, Zingaro $\mathrm{C}$, et al. Ultra fast-track minimally invasive aortic valve replacement: going beyond reduced incisions. Eur J Cardiothorac Surg. 2018;53(suppl_2):ii14-i8.

37. Williams JB, McConnell G, Allender JE, Woltz P, Kane K, Smith $\mathrm{PK}$, et al. One-year results from the first US-based enhanced recovery after cardiac surgery (ERAS Cardiac) program. J Thorac Cardiovasc Surg. 2019;157(5):1881-8 As the most extensive implementation of ERAS in cardiac surgery, this retrospective cohort analysis provides promising data of great value for further approaches.

38. Kubitz JC, Schulte-Uentrop L, Zoellner C, Lemke M, MessnerSchmitt A, Kalbacher D, et al. Establishment of an enhanced recovery after surgery protocol in minimally invasive heart valve surgery. PLoS One. 2020;15(4):e0231378.

39. Petersen J, Kloth B, Konertz J, Kubitz J, Schulte-Uentrop L, Ketels $G$, et al. Economic impact of enhanced recovery after surgery protocol in minimally invasive cardiac surgery. BMC Health Serv Res. 2021;21(1):254

Publisher's Note Springer Nature remains neutral with regard to jurisdictional claims in published maps and institutional affiliations. 